\title{
Desenvolvimento de um equipamento de grandes dimensões para análise de estruturas de pavimentos
}

\author{
Francis Massashi Kakuda; Alexandre Benetti Parreira²; Glauco Túlio Pessa Fabbri ${ }^{3}$
}

\begin{abstract}
Resumo: O artigo apresenta o desenvolvimento, a montagem e um exemplo de aplicação de um equipamento de grande porte (seção de 1,5 x 1,5m e altura de 1,2m) para o ensaio em laboratório de estruturas de pavimentos com materiais, espessuras de camadas e condições de carregamento similares às de campo. O carregamento cíclico é aplicado por um cilindro pneumático alimentado por um compressor de ar. A instrumentação é constituída de LVDTs, células de carga e de tensão total que permitem o monitoramento das cargas aplicadas, tensões no interior das camadas e deslocamentos elásticos e permanentes na superfície do pavimento. Com as bacias de deflexões determinadas a partir dos deslocamentos elásticos superficiais, é possível, por meio de retroanálise, o cálculo dos módulos de resiliência dos materiais constituintes das camadas ensaiadas. Os ensaios realizados até o presente indicam que o equipamento apresenta bom funcionamento, sendo que o sistema pneumático atende às expectativas, os transdutores fornecem medidas com a precisão exigida e os valores de módulo de resiliência calculados por meio da retroanálise são compatíveis com os determinados em ensaios triaxiais cíclicos e com os observados em campo em condições similares.
\end{abstract}

Abstract: The article presents the development, the assembly and an example of application of large-scale equipment (width of $1.5^{*} 1.5 \mathrm{~m}$ and height of $1.2 \mathrm{~m}$ ) for testing pavement structures in laboratory, with materials, layers thicknesses and loading conditions similar to the field ones. The load is cyclic and generated from a pneumatic actuator. The instrumentation is constituted of LVDTs, load-cells and soil pressure transducers that permit monitoring the applied loads and the stress distribution in the interior of the layers, as well as plastic and elastic deformations on the pavement surface. From the deflection basin obtained, it is possible, by means of backcalculation, the determination of the materials resilient modulus. In a preliminary analysis, the equipment showed a good operation, attended to the expectations and the transducers supplied measures with the required precision. The backcalculation results were compatible with those obtained from cyclic triaxial tests and those observed in similar field conditions.

\section{INTRODUÇÃO}

A infra-estrutura do transporte rodoviário nacional encontra-se envelhecida e o seu estado é precário em muitas regiões do país. Sabe-se que a escassez de recursos financeiros é fator preponderante no planejamento dos investimentos públicos. Assim, os grandes volumes de recursos exigidos na área da infraestrutura de transportes demandam que técnicas inovadoras de construção sejam incorporadas à prática da engenharia rodoviária de maneira a reduzir custos e aumentar a durabilidade de nossas estradas, garantido o retorno do capital investido.

Pesquisas realizadas em 2004 pelo Ministério dos Transportes demonstraram que $40,80 \%$ das rodovias federais são conceituadas como ruins; 30,90\% regular e apenas $28,3 \%$ são boas. Quanto à idade dos pavimentos, $80 \%$ da malha rodoviária apresentam mais de 10 anos; $15 \%$ de cinco a dez anos, e 5\%, idades inferiores a cinco anos.

\footnotetext{
${ }^{1}$ Francis Massashi Kakuda, Escola de Engenharia de São Carlos, Universidade de São Paulo, São Carlos, SP, Brasil. (e-mail: francis.kakuda@gmail.com).

${ }^{2}$ Alexandre Benetti Parreira, Escola de Engenharia de São Carlos, Universidade de São Paulo, São Carlos, SP, Brasil. (e-mail: parreira@usp.br).

${ }^{3}$ Glauco Túlio Pessa Fabbri, Escola de Engenharia de São Carlos, Universidade de São Paulo, São Carlos, SP, Brasil. (e-mail: glauco@sc.usp.br).

Manuscrito recebido em 2/12/2009 e aprovado para publicação em 20/2/2010. Este artigo é parte de TRANSPORTES, volume XVIII, número 2, junho de 2010. ISSN: 2237-1346 (online).
}

Na décima edição da pesquisa rodoviária CNT realizada em 2005, foram avaliados $81.944 \mathrm{~km}$ de rodovias em todo território nacional. Os resultados da pesquisa mostraram que apenas $17 \%$ da extensão das vias pesquisadas alcançaram conceito bom, e apenas $11 \%$ alcançaram o conceito ótimo. Os $72 \%$ restante das rodovias analisadas encontram-se em situações consideradas ruins ou péssimas, fato que compromete a segurança dos usuários, a competitividade dos mais variados setores produtivos e o desenvolvimento econômico do país. Dentre os defeitos encontrados nos pavimentos constataram-se desgastes, ondulações, buracos, trincas e remendos, e em alguns casos, a sua completa deterioração. Diante desta situação precária, é necessário o aporte de investimentos públicos e privados na área da infra-estrutura rodoviária, promovendo-se a manutenção, recuperação e modernização da malha existente e a sua ampliação, de maneira a garantir o crescimento e a competitividade do país.

A boa gestão dos recursos aplicados na área rodoviária requer que a concepção, o projeto e as técnicas utilizadas na construção, manutenção e recuperação de nossas estradas assegurem o retorno do capital investido. Assim, estudos devem ser desenvolvidos para que se avance no conhecimento do comportamento de estruturas de pavimentos e seja possível estabelecerem-se rotinas de projeto que contemplem os materiais, clima e tráfego das rodovias brasileiras.

Neste sentido, a utilização de um equipamento de ensaio de laboratório com grandes dimensões para o 
ensaio de seções de pavimentos em condições próximas às reais pode ser uma ferramenta de grande utilidade na concepção e projeto de pavimentos, possibilitando a análise do efeito da incorporação de novos materiais, diferentes técnicas construtivas e tipos de carregamentos, etc. Dentre os estudos em que se utilizaram equipamentos de grandes dimensões no estudo de pavimentos, destacam-se as pesquisas desenvolvidas por Perkins (1999), Tingle and Jersey (2005), Kim et al. (2005), Leng and Garb (2002, 2007) e Silva (2009).

\section{OBJETIVO}

O objetivo deste artigo é apresentar o desenvolvimento, a montagem e um exemplo de aplicação de um equipamento de grande porte dotado de recursos que possibilitam o ensaio em laboratório de estruturas de pavimentos com materiais, espessuras de camadas e condições de carregamento similares aos encontrados em campo. A instrumentação usada no equipamento permite o monitoramento das cargas aplicadas, tensões no interior das camadas e deslocamentos elásticos e permanentes em pontos variados da superfície do pavimento alinhados segundo uma reta com origem no centro da área carregada. Com base nas bacias de deflexões determinadas a partir dos deslocamentos superficiais medidos, é possível, por meio de retroanálise, a determinação dos módulos de resiliência das camadas constituintes da estrutura ensaiada.

\section{DESENVOLVIMENTO E DESCRIÇÃO DO EQUIPAMENTO}

Para o desenvolvimento do equipamento, partiu-se da idéia da construção de uma caixa metálica quadrada com dimensões suficientes para a inserção e o ensaio de uma seção de pavimento com medidas em escala próxima à de campo e a sua solicitação através de carregamento pneumático cíclico equivalente ao imposto pelo tráfego e aplicado na superfície da estrutura por meio de uma placa circular semi-flexível.

A espessura do subleito utilizado na composição do pavimento e as dimensões da caixa de ensaio foram definidas a partir de análises numéricas elásticas realizadas utilizando o programa de elementos finitos PLAXIS, versão 8.2. O PLAXIS é um programa computacional bi-dimensional concebido para realizar análises de deformações, deslocamentos e estabilidade para vários tipos de aplicações geotécnicas. Situações reais podem ser simuladas por meio de análises planas ou axissimétricas utilizando modelos elásticos lineares, elásticos perfeitamente plásticos, e outros. O programa conta com uma interface gráfica que permite ao usuário gerar malhas de elementos finitos triangulares de 6 ou 15 nós.

Para as análises, foi definida uma estrutura de pavimento flexível composta de uma capa de CBUQ (concreto betuminoso usinado a quente) e uma base granular sobreposta a um subleito, representado por uma camada de solo. Estes elementos foram inseridos em uma estrutura indeformável, simulando a caixa de ensaios de aço. Assumiu-se que os materiais apresen-

Tabela 1. Programa PLAXIS - Módulo de elasticidade e coeficiente de Poisson dos materiais e espessuras das camadas que compõem o pavimento - Etapa de análise das dimensões do equipamento

\begin{tabular}{|c|c|c|c|}
\hline Materiais & $\begin{array}{c}\text { Módulo de elasticidade } \\
\left(\mathrm{kN} / \mathrm{m}^{2}\right)\end{array}$ & Coeficiente de Poisson & $\begin{array}{l}\text { Espessura } \\
\quad(\mathrm{cm})\end{array}$ \\
\hline Capa asfáltica & $3,5 \times 10^{6}$ & 0,33 & 7,0 \\
\hline Base granular & $4,5 \times 10^{5}$ & 0,35 & 40,0 \\
\hline Subleito & $4,5 \times 10^{4}$ & 0,30 & Variável ou 50,0cm \\
\hline
\end{tabular}

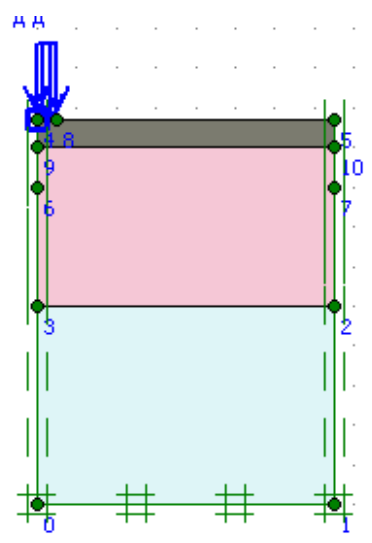

(a)

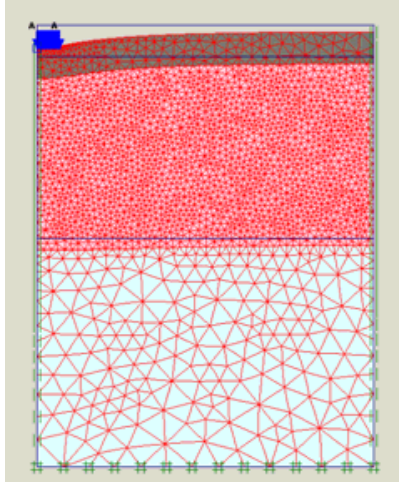

(b)

Figura 1. Simulação de meia seção de pavimento segundo saída gráfica do Programa PLAXIS: (a) vínculos e carregamento e (b) malha-deformada pelo carregamento 
tam comportamento elástico-linear com características mecânicas compatíveis com as de materiais encontrados em rodovias brasileiras. A Tabela 1 apresenta os módulos de elasticidade e os coeficientes de Poisson dos materiais e as espessuras das camadas que compõem o pavimento nesta etapa preliminar do estudo.

Para o carregamento da seção do pavimento, supôsse, nesta análise, uma roda de um eixo-padrão de rodas duplas com pressão de contato de até $550 \mathrm{kPa}$ e raio de $10,8 \mathrm{~cm}$. Esta configuração foi adotada somente nesta etapa preliminar do estudo. Outras configurações foram analisadas posteriormente, conforme descrito no item 3.3. A Figura 1 ilustra, segundo a saída gráfica do Programa PLAXIS, os vínculos, o carregamento e a malha de elementos finitos de uma simulação da seção do pavimento para as condições descritas.

\subsection{Análise da influência da espessura do subleito}

Para a definição da espessura mínima do subleito a partir da qual esta variável não mais interfere nos resultados do experimento, foram realizadas simulações numéricas variando-se esta dimensão e determinando as correspondentes bacias de recalque na superfície da seção descrita na Tabela 1 . Nesta etapa do estudo, adotou-se uma caixa circular com diâmetro de 3m, dimensão suficiente para que as paredes do equipamento não interferissem nos resultados, conforme discutido no item 3.2. Observou-se que a partir de uma espessura de subleito de $50 \mathrm{~cm}$, ocorria a convergência para uma bacia única de recalques. Nesta condição, a tensão vertical no horizonte inferior da camada sob a vertical do carregamento é da ordem de menos de $2 \%$ da carga aplicada na superfície. Este valor, sub-leito com $50 \mathrm{~cm}$, foi então adotado nas análises subseqüentes e na montagem do ensaio descrito no item 4, "Exemplo da Aplicação do Equipamento”.

\subsection{Análise das dimensões da caixa}

Para a definição das dimensões mínimas da caixa de ensaios a partir da qual as paredes não interferem nos resultados do experimento, foram realizadas simulações axissimétricas para caixas circulares com diâmetros de 1,5, 2,0 e 3m, determinando-se as correspondentes bacias de recalque na superfície da seção descrita na Tabela 1 para um subleito de $50 \mathrm{~cm}$ de espessura, conforme definido anteriormente.

É importante destacar que os vínculos nas paredes verticais da caixa permitem movimentação nesta direção. Simulações preliminares realizadas com vínculos fixos nas duas direções mostraram que nesta condição existe uma influência muito grande das paredes da caixa nos resultados, o que exigiria a construção de uma estrutura de dimensões não compatíveis com o espaço disponível no laboratório. Para se garantir o movimento vertical livre da estrutura do pavimento com relação à caixa, procurou-se a minimizar o atrito com a instalação nas laterais do equipamento de uma geo-membrana impregnada com graxa.

A Figura 2 apresenta as bacias de recalques fornecidas pelo Programa PLAXIS para as três dimensões de caixa testadas e também a bacia obtida por meio de uma simulação usando o programa computacional ELSYM-5, que corresponde a uma situação onde não existiria nenhuma restrição lateral ao desenvolvimento dos deslocamentos.

Analisando-se a Figura 2, observa-se que as bacias previstas pelo programa PLAXIS diferem pouco para os diâmetros de 2 e 3m, principalmente no trecho central da curva, podendo-se concluir que a partir deste último valor, as paredes não mais influenciariam significativamente os resultados. A bacia para 1,5m apresenta recalques maiores que os correspondentes às maiores dimensões, entretanto a forma conserva-se a mesma. Com base nestes resultados, poder-se-ia concluir que o diâmetro de $3 \mathrm{~m}$ seria o ideal e que a partir de $2 \mathrm{~m}$, a influência das paredes seria muito pequena. Entretanto, o espaço disponível no Laboratório de Estradas da EESC/USP era reduzido, dificultando a instalação de uma caixa com lados maiores que $1,5 \mathrm{~m}$.

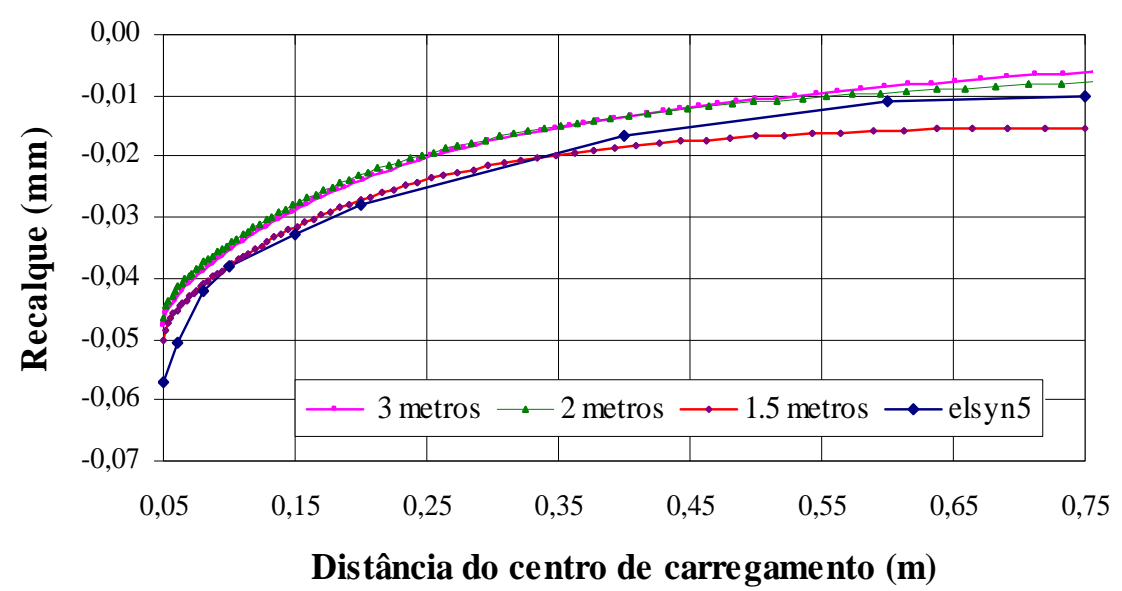

Figura 2. Programa PLAXIS e ELSYN-5 - Bacias de recalque para caixas com diferentes dimensões 
Assim, procurou-se avaliar a conseqüência de se adotar a medida de $1,5 \mathrm{~m}$ de lado para a construção da caixa.

Comparando-se as bacias obtidas nas simulações usando o PLAXIS para 1,5 e 3,0m, esta última considerada a medida ideal, observa-se que a diferença, no centro do carregamento, é de aproximadamente 5\%. Comparando-se a bacia de $1,5 \mathrm{~m}$ com a obtida a partir do programa ELSYM-5, muito utilizado na análise e retroanálise de pavimentos, observa-se que os recalques no centro do carregamento são coincidentes, além de que a bacia obtida do ELSYM-5 aproxima-se mais da bacia de $1,5 \mathrm{~m}$ que da $3 \mathrm{~m}$, considerada a ideal.

Finalmente, com base nestas conclusões e considerando o grande volume de material e o trabalho exigido para a compactação das seções a serem ensaiadas para caixas com dimensões muito avantajadas e além das limitações de espaço, optou-se por construir uma caixa de ensaios de seção quadrada com $1,5 \mathrm{~m}$ de largura e altura de $1,2 \mathrm{~m}$. A altura foi definida de maneira a permitir a construção de uma seção de pavimento composta por um subleito de $50 \mathrm{~cm}$ e uma base e uma capa com espessuras compatíveis com a de pavimen-

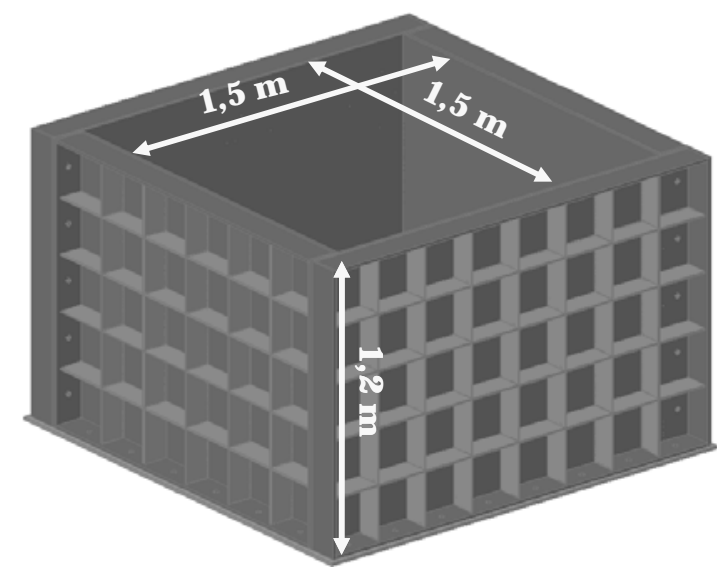

Figura 3. Perspectiva e dimensões da caixa de ensaios

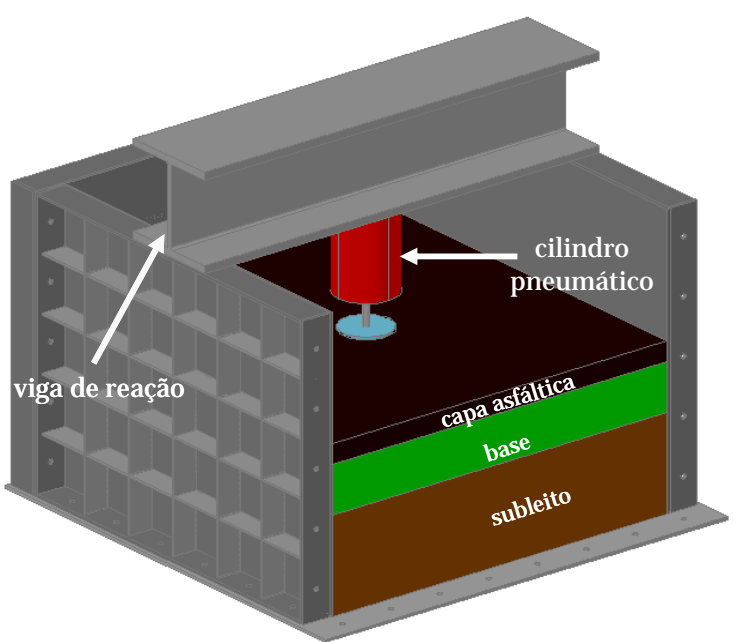

(a) tos reais. A Figura 3 apresenta uma perspectiva da caixa de ensaios, destacando as laterais dotadas de nervuras tipo colméia para se garantir a rigidez das paredes.

\subsection{Sistema de carregamento}

O sistema responsável pela geração do carregamento cíclico é composto de um cilindro pneumático de 300mm de diâmetro alimentado por um compressor de 15HP acoplado a duas válvulas reguladoras, uma de serviço pesado e outra proporcional, para o controle de pressão e vazão de entrada de ar, associadas, em série, a um reservatório auxiliar de 21 de capacidade, usado com a função de abreviar o tempo de aplicação do pulso. O carregamento é aplicado na superfície da seção ensaiada por meio de uma placa metálica circular com 300mm de diâmetro e 25,4mm de espessura. Um elemento de borracha com $4 \mathrm{~mm}$ de espessura foi instalado na face inferior da placa para torná-la semiflexível e evitar que ocorram rupturas localizadas no terreno sob as suas extremidades e aproximar as condições do experimento às condições de campo.

Quando se utiliza a placa descrita anteriormente e são aplicadas cargas cíclicas de $40 \mathrm{kN}$, com duração de $1 \mathrm{~Hz}$, reproduz-se a condição preconizada para o ensaio 'Determinação das Deflexões Utilizando o Deflectômetro de Impacto Tipo Falling Weight Deflectometer - FWD, segundo a norma DNER-PRO 273/96. Nestas condições, é aplicada na superfície do pavimento uma tensão de $550 \mathrm{kPa}$. O equipamento permite ainda a utilização de placas de outras dimensões e a aplicação de cargas de magnitudes diversas, possibilitando variar-se a configuração do carregamento.

A Figura 4a ilustra, esquematicamente, a caixa de ensaios e uma seção de pavimento, o cilindro pneumático ancorado à viga metálica de reação (Seção I, CS 400x248mm) e a placa circular. Na Figura 4b, a foto

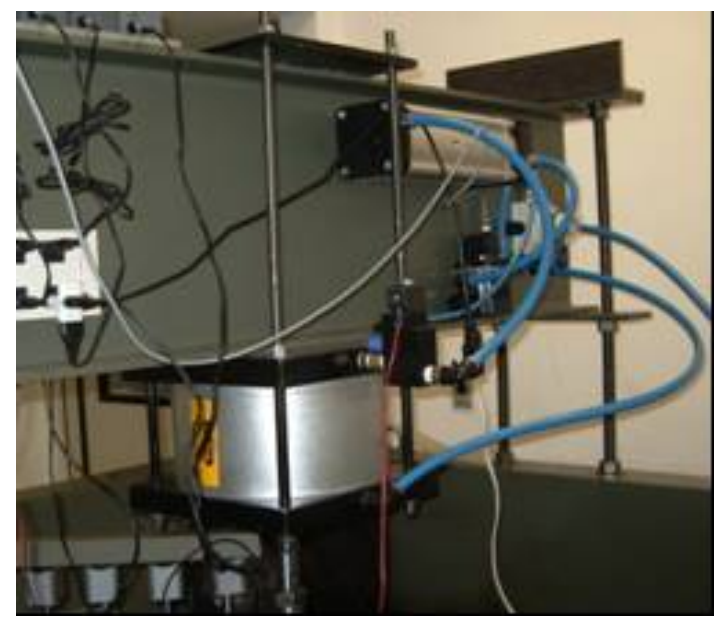

(b)

Figura 4. Caixa de ensaios: (a) visão geral esquemática; (b) viga de reação, cilindro pneumático, válvulas de controle e reservatório de ar auxiliar 
mostra um detalhe da viga de reação, o cilindro pneumático, as válvulas de controle e o reservatório auxiliar de ar.

\subsection{Instrumentação, controle do ensaio e aquisição de dados}

A instrumentação é composta por transdutores para a medida da força aplicada, deslocamentos na superfície da seção ensaiada e tensões no interior das camadas. A força é monitorada por uma célula de carga acoplada ao cilindro pneumático e os deslocamentos superficiais são monitorados por seis LVDTs alinhados e apoiados sobre a superfície do pavimento, cinco deles posicionados fora da região carregada, e um posicionado em um pequeno orifício na placa, próximo ao seu centro (o LVDT está apoiado diretamente sobre a superfície do pavimento, não sendo afetado pela vibração da placa). Quatro células de tensão total foram instaladas sob a vertical do carregamento, um par no horizonte correspondente à interface do subleito com a base e o outro par, no horizonte médio da base. Para cada um dos pares, uma das células foi instalada de maneira a fornecer a tensão vertical e a outra, a tensão horizontal. A Figura 5 apresenta uma vista esquemática em corte da caixa de ensaios e a disposição dos transdutores (a), e uma foto que ilustra a placa carregada, o LVDT sobre o furo da placa e o restante dos LVDTs alinhados (b).

Para o controle do ensaio e a aquisição dos dados foi utilizado um computador dotado de duas placas multi-canais (16 bit, 500 kS/s) da National Instruments e condicionadores de sinais. O programa utilizado para o tratamento das leituras fornecidas pelos medidores de deslocamentos e células foi desenvolvido pelo Prof. Glauco Tulio Pessa Fabbri, sendo utilizada a plataforma LabView. Para melhor visualização dos gráficos de saída foram utilizados dois monitores. A Figura 6 apresenta uma vista panorâmica do equipamento durante a execução de um ensaio, sendo que ao fundo aparecem os referidos monitores.

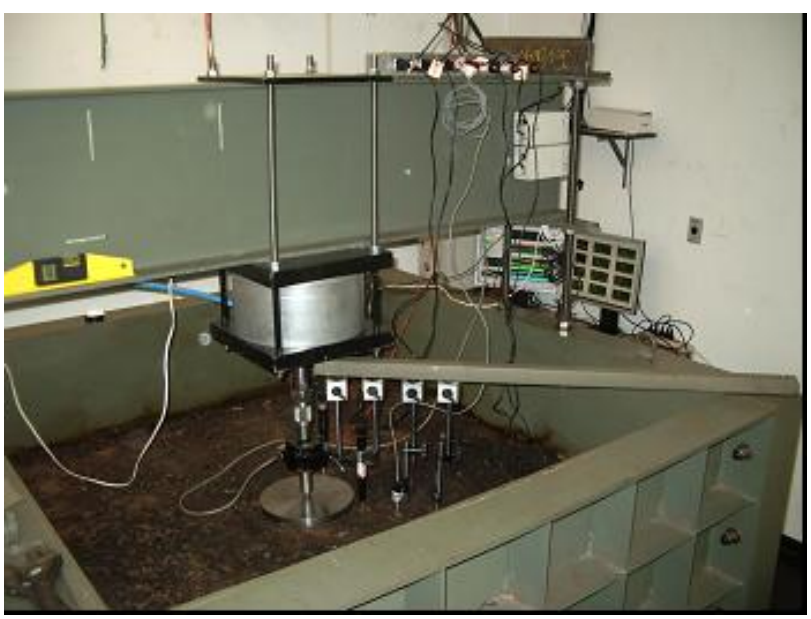

Figura 6. Vista geral do equipamento de ensaio

As Figuras 7 e 8 ilustram a saída gráfica do programa de aquisição de dados conforme apresentados nos monitores 1 e 2, respectivamente. Nestas figuras, cada um dos campos da tela foi numerado para facilitar a descrição de seus conteúdos. Na Figura 7, foram destacados sete campos, sendo que suas funções são descritas em seguida. Campo 1: bacia de recalque atualizada a cada aplicação de carga; 2: deformação permanente acumulada sob o centro da placa; 3: tensões totais nos dois horizontes instrumentados; 4: deslocamentos de cada um dos LVDTs a cada ciclo de carga; 5: deslocamento acumulado da placa; 6: deslocamento da placa a cada ciclo de carga e 7: carga aplicada.

Na Figura 8 foram destacados 12 campos, cujas funções são descritas a seguir. Campos 1 a 4: tensões totais horizontais e verticais nos horizontes instrumentados; 5: distribuição da força durante cada pulso de carga; 6 a 11: distribuição dos deslocamentos durante cada pulso de carga para cada um dos transdutores apresentados isoladamente; 12: mesma variável descrita anteriormente apresentada para o conjunto dos transdutores.

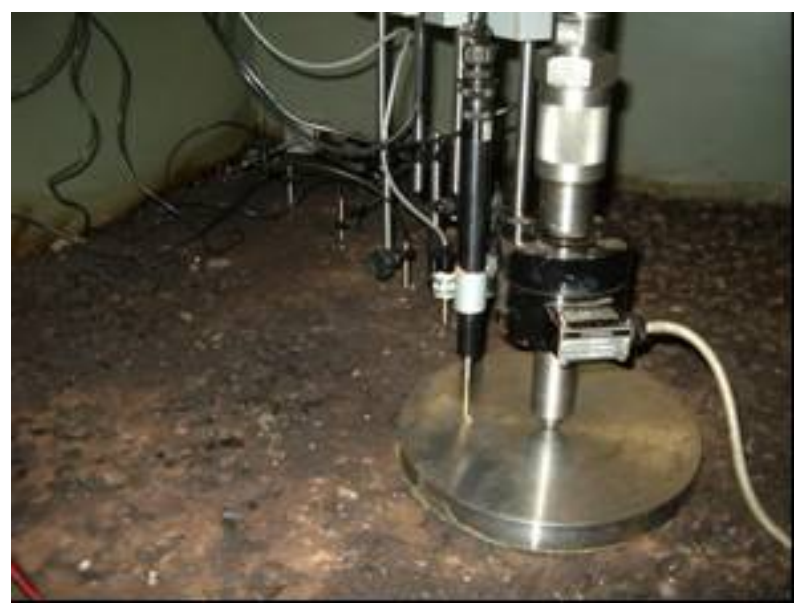

(b)

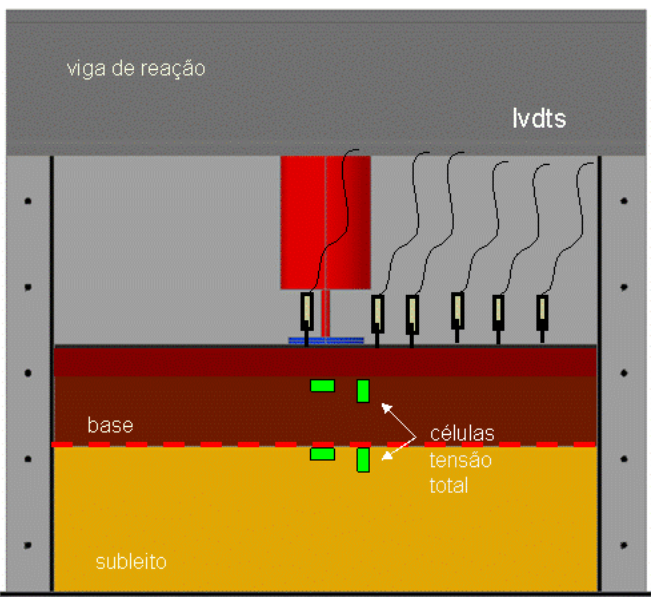

(a)

Figura 5. Vista (a) esquemática do posicionamento da instrumentação; (b) disposição LVDTs 


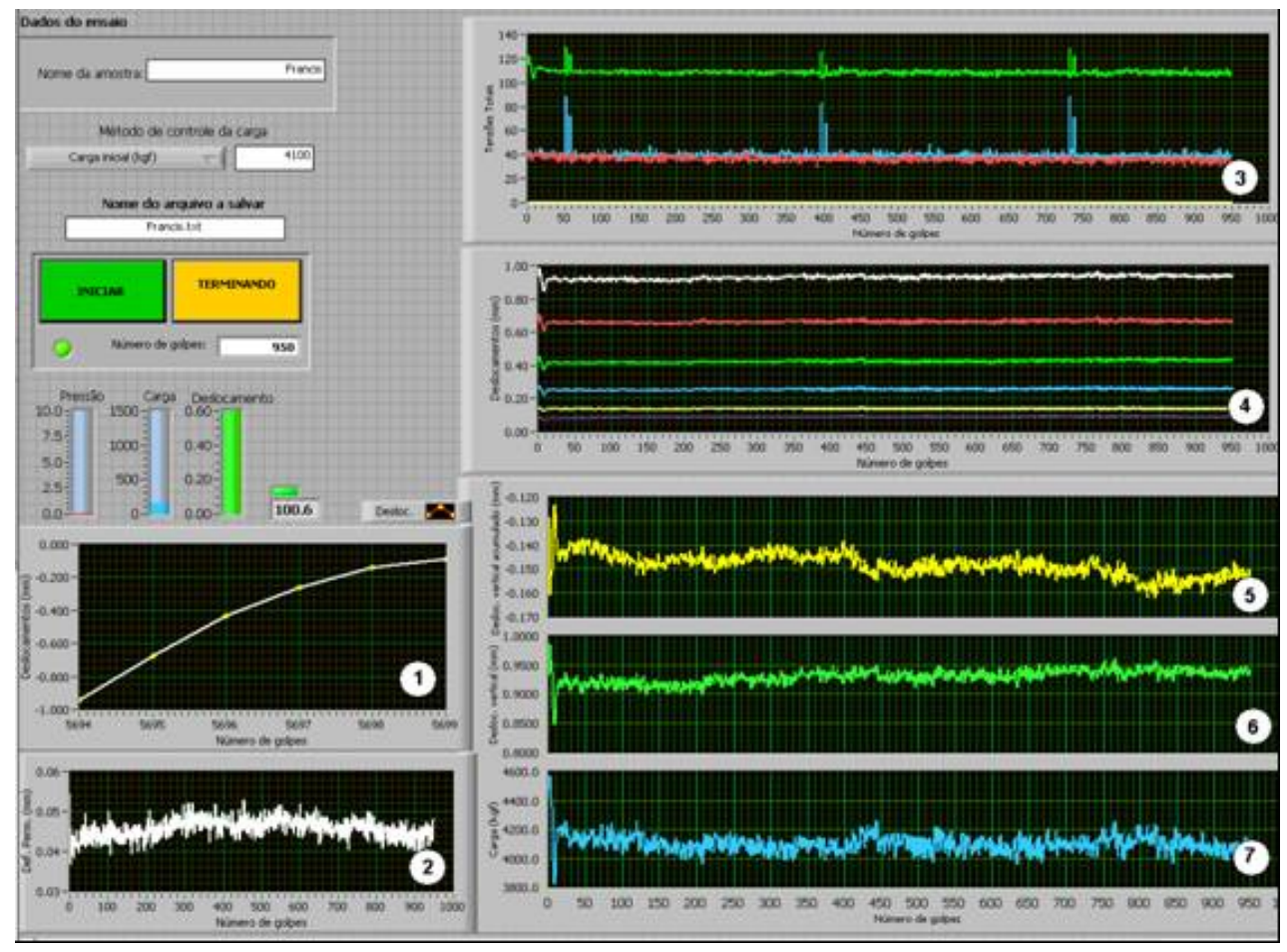

Figura 7. Saída gráfica do programa - monitor 1

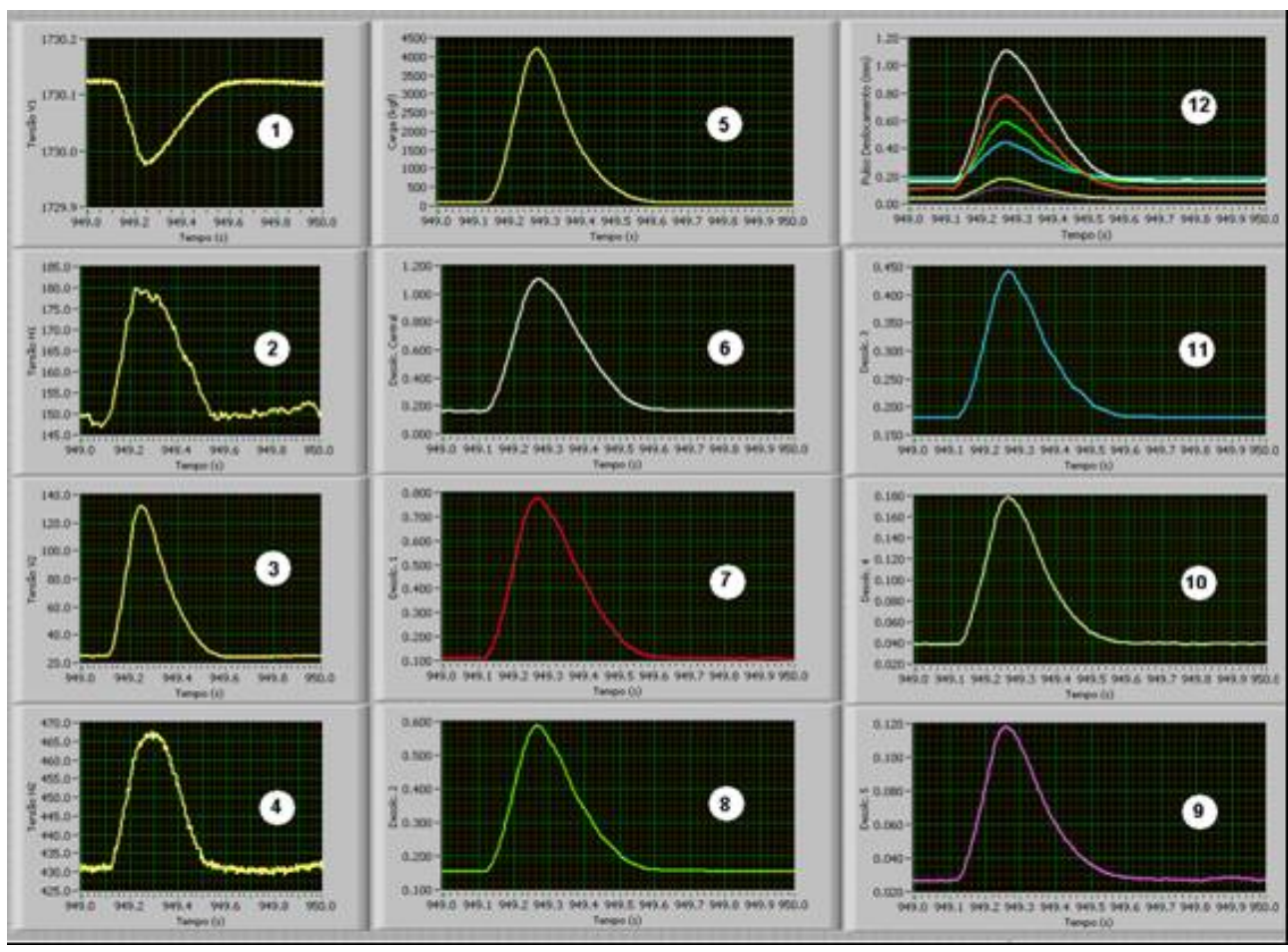

Figura 8. Saída gráfica do programa - monitor 2

\section{EXEMPLO DE APLICAÇÃO DO EQUIPAMENTO}

Para a primeira aplicação do equipamento, estudou-se uma seção constituída por uma base de solo-brita com $20 \mathrm{~cm}$ de espessura sobreposta a um subleito argiloso de baixa capacidade de suporte $\mathrm{com} 50 \mathrm{~cm}$ de espessura.

Nesta aplicação, foram analisadas duas configurações de carregamento. Na primeira, utilizou-se uma carga cíclica de $20 \mathrm{kN}$ aplicada em uma placa de $25 \mathrm{~cm}$ de diâmetro, resultando em uma pressão de contato de $412 \mathrm{kPa}$. Na segunda, utilizou-se uma carga cíclica de $40 \mathrm{kN}$ aplicada em uma placa de $30 \mathrm{~cm}$, resultando numa pressão de contato de $550 \mathrm{kN}$. A frequência do carregamento empregada em ambas as configurações foi de $1 \mathrm{~Hz}$, sendo cada ciclo composto por um período de 0,3 s correspondente à aplicação da carga, seguido de um período de $0,7 \mathrm{~s}$ correspondente ao repouso. $\mathrm{O}$ tempo de carregamento de $0,3 \mathrm{~s}$ foi determinado em 
razão de limitações do sistema pneumático que não permitiram que se alcançassem os patamares de carga especificados em $0,1 \mathrm{~s}$, à semelhança do preconizado para a realização de ensaios triaxiais cíclicos. As bacias de recalque obtidas ao final da aplicação de $10^{5}$ ciclos de carga foram retroanalisadas, permitindo a obtenção dos módulos de resiliência dos materiais. As deformações permanentes ao longo dos ciclos de carregamento também foram determinadas, entretanto, não foram analisadas nesta fase da pesquisa.

\subsection{Materiais}

Para a construção da seção do pavimento foram utilizados dois solos e uma brita. Um dos solos foi usado como subleito, e o outro, juntamente com a brita, para a composição da mistura solo-brita na proporção de $30 \%$ de solo e $70 \%$ de brita usada na base.

Os dois solos são provenientes de taludes de rodovias do Estado de São Paulo. O solo utilizado como subleito, denominado Solo 1, foi coletado no km 34, do lado esquerdo da Rodovia Castelo Branco (SP280), sentido Barueri - Capital. O solo utilizado na composição da mistura solo-brita, denominado Solo 2, foi coletado no $\mathrm{km} 152+500 \mathrm{~m}$, do lado esquerdo da Rodovia Prof. Luis Augusto de Oliveira (SP-215), sentido São Carlos - Ribeirão Bonito.

As classificações dos solos segundo os sistemas S.U.C.S., H.R.B e MCT são, respectivamente, para o Solo 1, A-4, CL e NS'; e para Solo 2, A-2-6, SC e LA'. O agregado pétreo empregado na composição da mistura solo-brita é de natureza basáltica e foi coletado na Pedreira Bandeirantes, localizada no Município de São Carlos.

O agregado foi submetido ao ensaio de Abrasão Los Angeles (DNER ME 035/94) e apresentou desgaste da ordem de $17 \%$, valor inferior ao limite de $55 \%$ preconizado pela norma DNER ES 303/97 para a construção de bases estabilizadas granulometricamente. Os materiais usados na composição do subleito e da base foram compactados nas energias normal e modificada do ensaio Proctor (DNER-ME 129/94), respectivamente. Também foram realizados ensaios para a determinação dos Índices de Suporte Califórnia (DNER ME 049/94). Os resultados destes ensaios são apresen- tados na Tabela 2.

Foram também realizados ensaios triaxiais cíclicos segundo a norma "Standard Method of Test for Determining the Resilient Modulus of Soil and Aggregate Materials" (AASHTO Designation: T307-99). A Tabela 3 apresenta as constantes $k_{1}, k_{2}$ e $k_{3}$ do modelo composto (Equação 1) e os respectivos coeficientes de determinação $\mathrm{R}^{2}$ para os materiais do subleito e base.

$$
M_{R}=k_{1} \cdot \sigma_{3}^{k_{2}} \cdot \sigma_{d}^{k_{3}}
$$

em que,

$M_{R}$ : módulo de resiliência (MPa);

$\sigma_{d}$ : tensão desvio $(\mathrm{kPa})$;

$\sigma_{3}:$ tensão confinante $(\mathrm{kPa})$;

$k_{1}, k_{2}$ e $k_{3}$ : parâmetros de regressão.

Na construção da seção do pavimento, o subleito de $50 \mathrm{~cm}$ foi compactado a partir de camadas de $5 \mathrm{~cm}$, observando-se um desvio de umidade inferior a $0,1 \%$ e um grau de compactação de no mínimo 98,5\%. Para a base de $20 \mathrm{~cm}$, foram compactadas duas camadas de $7 \mathrm{~cm}$, seguidas de uma camada de $6 \mathrm{~cm}$, observando-se um desvio de umidade inferior a $0,3 \%$ e um grau de compactação de $100 \%$.

\subsection{Apresentação e análise dos resultados}

A Figura 9 apresenta as bacias de deflexões correspondentes a 1.000, 10.000, 50.000 e 100.000 aplicações da primeira configuração do carregamento, ou seja, carga cíclica de $20 \mathrm{kN}$ e placa de $25 \mathrm{~cm}$; a Figura 10 apresenta a bacia de deflexões correspondente a 100.000 aplicações da segunda configuração do carregamento, ou seja, carga cíclica de $40 \mathrm{kN}$ e placa de $30 \mathrm{~cm}$.

A partir da bacia de deflexões obtida para 100.000 aplicações do carregamento, obtiveram-se os módulos de resiliência da camada de base e do subleito por meio de retroanálise para as duas configurações de carregamento. O programa utilizado na retroanálise foi desenvolvido pelo Prof. Dr. Glauco Tulio Pessa Fabbri em plataforma LabView a partir do programa ELSYM-5. A Tabela 4 apresenta os módulos de resiliência obtidos na retroanálise e a partir do modelo composto (Equação 1). Para o cálculo dos módulos de resiliência com modelo composto, foram considerados

Tabela 2. Resultados dos ensaios de compactação e CBR do subleito e da base

\begin{tabular}{|c|c|c|c|c|c|}
\hline Material & $\begin{array}{c}\text { Energia de } \\
\text { compactação }\end{array}$ & Aplicação & $\begin{array}{l}W_{o t} \\
(\%)\end{array}$ & $\begin{array}{c}\rho_{d \max } \\
\left(\mathrm{g} / \mathrm{cm}^{2}\right)\end{array}$ & $\begin{array}{c}\text { CBR na } W_{\text {ot }} \\
(\%)\end{array}$ \\
\hline Solo & Normal & subleito & 25,7 & 1,459 & 8 \\
\hline Solo/brita & Modificada & base & 5,6 & 2,315 & 190 \\
\hline
\end{tabular}

Tabela 3. Módulo de resiliência - modelo composto (Equação 1)

\begin{tabular}{cccccc}
\hline \multirow{2}{*}{ Material } & \multicolumn{3}{c}{ Parâmetros de regressão } & \multirow{2}{*}{$\boldsymbol{R}^{2}$} \\
\cline { 2 - 5 } & $k_{1}$ & $k_{2}$ & $k_{3}$ & 0,93 \\
Subleito & 29,00 & 0,52 & $-0,44$ & 0,96 \\
\hline Base & 63,59 & 0,78 & $-0,35$ & 0,96 \\
\hline
\end{tabular}


os estados de tensão correspondentes aos horizontes médios da base e do subleito determinados com o programa ELSYM-5 para cada um dos carregamentos.

Analisando-se a Tabela 4 e comparando os módulos obtidos a partir da retroanálise com os módulos obtidos a partir dos ensaios triaxiais cíclicos, observa-se que os valores são de mesma ordem de grandeza, apesar da diferença ser bastante pequena para a base, menor que $1 \%$, considerando a média determinada para duas condições de carregamentos, e elevada para o subleito, em torno de $76 \%$, considerando o mesmo cálculo.

Supõe-se que a maior concordância dos resultados referentes à base deva-se à associação de alguns fatos: a menor espessura desta camada, $20 \mathrm{~cm}$ comparada com os $50 \mathrm{~cm}$ do subleito, faz com que as tensões no horizonte médio da camada usadas no cálculo do MR por meio do modelo composto sejam mais representativas das tensões ao longo deste elemento do que as tensões no horizonte médio do subleito usadas nas mesmas condições; o valor do MR do subleito é muito baixo se comparado com a rigidez da maioria do ma- teriais presentes em obras rodoviárias e assim, os erros inerentes às medidas realizadas nos ensaios são relativamente elevados se comparados ao valor real do módulo; o material usado no subleito mostrou-se de difícil manipulação durante a compactação dos corposde-prova e a compactação desta camada na caixa de ensaios, apesar destas operações terem merecido todo cuidado e atenção.

Finalmente, considerando-se que a seção ensaiada no equipamento de grandes dimensões aproxima-se mais da realidade de campo e que os resultados obtidos nesta condição levem em conta aspectos relacionados à interação dos diferentes materiais e camadas, diferentemente de estudos realizados a partir de resultados de ensaios triaxiais cíclicos, acredita-se que este enfoque agregue maior confiabilidade à análise. Supõe-se ainda que nas etapas subseqüentes do estudo, o uso de modelos não lineares nas retroanálises possa contribuir para o aprimoramento dos resultados.

\section{CONSIDERAÇÕES FINAIS}

Pode-se afirmar que o equipamento mostrou um bom

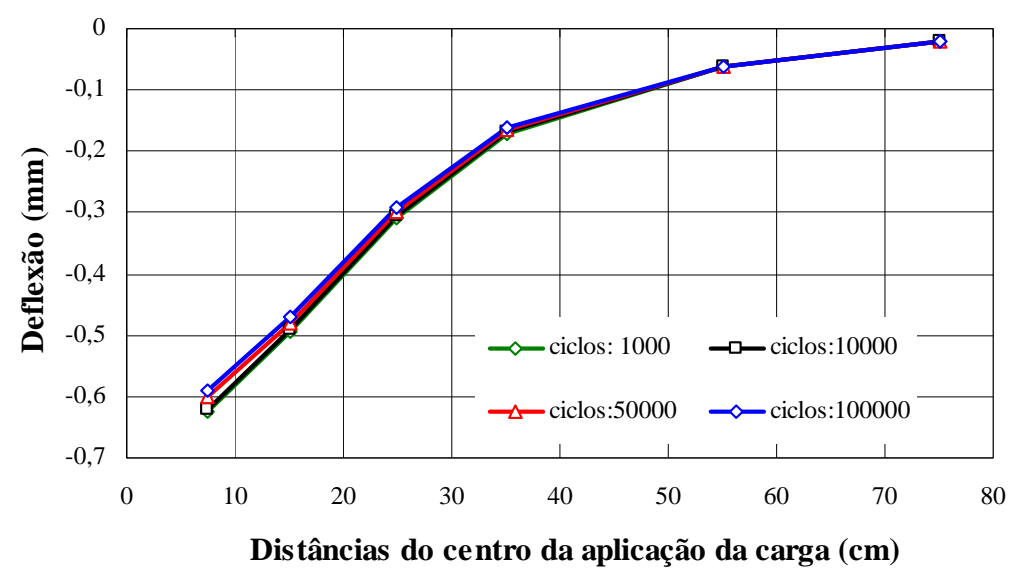

Figura 9. Bacias de deflexões para a primeira configuração de carregamento

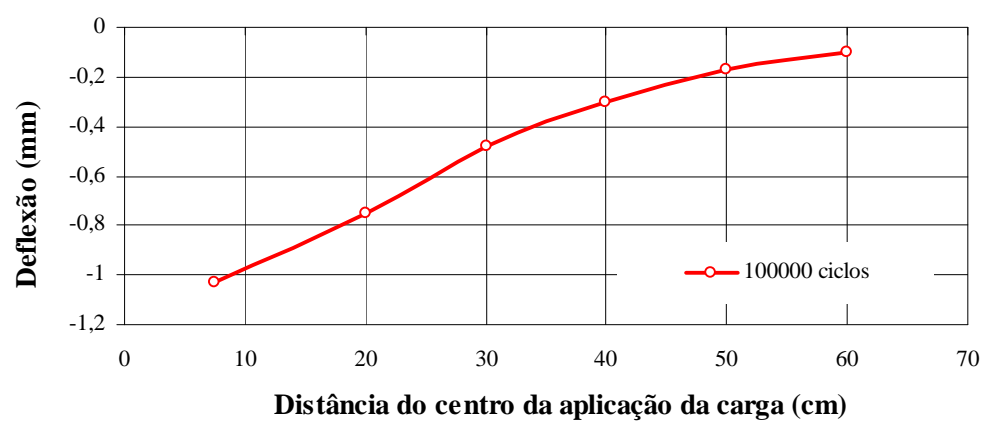

Figura 10. Bacia de deflexões para a segunda configuração de carregamento

Tabela 4. Módulos de resiliência - ensaio triaxial e retroanálise das bacias de deflexões

\begin{tabular}{|c|c|c|c|c|}
\hline \multirow{4}{*}{ Camadas } & \multicolumn{2}{|c|}{ Primeiro carregamento } & \multicolumn{2}{|c|}{ Segundo carregamento } \\
\hline & $M R(M P a)$ & $M R(M P a)$ & $M R(M P a)$ & $M R(M P a)$ \\
\hline & Ensaio triaxial & Retroanálise & Ensaio triaxial & Retroanálise \\
\hline & Equação 1 & da bacia & Equação 1 & da bacia \\
\hline Subleito & 19 & 29 & 20 & 40 \\
\hline Base & 250 & 265 & 310 & 294 \\
\hline
\end{tabular}


funcionamento, sendo que o sistema pneumático atende às expectativas, os transdutores fornecem medidas com a precisão exigida e os valores de módulo de resiliência calculados por meio da retroanálise são compatíveis com os determinados em ensaios triaxiais cíclicos e com os observados em campo em condições similares.

\section{AGRADECIMENTOS}

Os autores agradecem à FAPESP pelo apoio financeiro para construção do equipamento e à CAPES pela bolsa de doutorado concedida ao primeiro autor.

\section{REFERÊNCIAS BIBLIOGRÁFICAS}

AASHTO Designation: T307-99. "Standard Method of Test for Determining the Resilient Modulus of Soil and Aggregate Materials".

DNER-ME 035/94. Agregado - Abrasão "Los Angeles”..

DNER-ES 303/97. "Pavimentação - Base estabilizada granulometricamente".

DNER-PRO 273/96. "Determinação das Deflexões Utilizando o Deflectômetro de Impacto Tipo Falling Weight Deflectometer - FWD".

DNER ME 049/94. "Solos-determinação do índice de Suporte Califórnia utilizando amostra não trabalhadas".

DNER-ME 129/94. "Solos-compactação utilizando amostras não trabalhadas”.

Guimarães, A. C. R.(2009) - "Um Método Mecanístico Empírico para a Previsão da Deformação Permanente em Solos Tropicais Constituintes de Pavimentos.” Tese de Doutorado - Rio de Janeiro: UFRJ/COPPE.

Kim, W. H. et al. (2005). "Structural contribution of geosyntheticreinforced working platforms in flexible pavement”. TRR 1936, Transportation Research Board.

Leng, J. and Gabr, M. A. (2002). "Characteristics of geogrid-reinforced aggregate under cyclic load”. TRR 1786, Transportation Research Board.

Leng, J. and Gabr, M. A. (2007). "Deformation-resistance model for geogrid-reinforced unpaved road”. TRR 1975, Transportation Research Board.

NBR 7182. Solo - Ensaio de compactação. Rio de Janeiro, 1986

Perkins, S. W., (1999) "Mechanical response of geosynthetic-reinforced flexible pavement”. Geosynthetic International - vol 6

Silva, B. H. (2009) - "Análise Mecânica de um Pavimento Rodoviário Submetido à Oscilação do Lençol Freático Simulada em Modelo Físico de Verdadeira Grandeza”. Tese de Doutorado - Rio de Janeiro: UFRJ/COPPE

Tingle, J. S. and Jersey, S. R. (2005). "Cyclic plate load testing of geosynthetic-reinforced unbound aggregate roads”. TRR-1936, Transportation Research Board. 